\title{
SOBRE LA LOCALIZACIÓN DE SEGOBRIX Y LAS MONEDAS DEL YACIMIENTO DE CLUNIA*
}

\author{
P()R \\ M. PAZ GARCIA-BELLIDO \\ Departamento de llistoria Antigua y Aryueologia, C.F.II. C.S.I.C. (Madrid)
}

A la memoria del Dr. Joan Maluquer de Motes

\section{RESUMEN}

Con nuevos datos numismáticos y revisión de los epigrafieos y literarios, se insiste en la imposibilidad de que la Segobrix republicana estuviera en Cabeza de Griego (Cuenca). Sin embargo, si debió ser éste el emplazamiento de la Segobriga imperial, atestiguado por la presencia en la zona de su moneda augústea y tiberiana. Es posible que tras las guerras sertorianas se traladase la ciudad desde la Meseta norte a Cabeza de Griego, ocasionando este nuevo e importante emplazamiento el final de la ciudad cercana de Contrebia Carbica.

\section{SUMMARY}

With new numismatic data and the revision of the old epigraphic and literary texts, the $\mathrm{A}$. insists on the impossibility to identificate the Republican city of Segobrix with (abeza de Griego (Cuenca), although this last settlement was surely the place of the Imperial Segobriga. The inhabitants of Segobrix were probably moved, after Sertorius time, from the nuclear area of the Meseta Norte, near Clunia, to another city in the Meseta Sur, Segobriga in Cuenca.

En 1974, con motivo de la publicación de un tesorillo de denarios ibéricos hallado en Salamanca, defendi que la ciudad celtibérica de Segobrix - como debian pronunciar los celtiberos-cuyo único legado histórico de momento han sido sus emisiones de denarios, ases y semises, amén de unas pocas y equivocas referencias literarias, no debia buscarse en las ruinas de la Segobriga de Cabeza de Griego, sino en

- Este texto fue entregado para el Homenaje al Dr. Maluquer en 1986; van ahora nuevos datos y propuestas que hoy desgraciadamente debo ofrecer en su memoria. la mesopotamia del Duero y el Pisuerga ${ }^{1}$. Mis argumentos se basaban entonces en el área de dispersión de las monedas de esta ceca y desde entonces ningún testimonio nuevo ha venido a contradecirlos, más al contrario, cuando tropiezo con nuevas referencias de hallazgos, resultan siempre reiterativas, acumulándose en la Celtiberia de la Meseta norte. Lo que ofrezco ahora es el estudio de nuevos hallazgos de la moneda de śekobirikes, marcando mi énfasis esta vez, más en las piezas de bronce que en las de plata, al contrario de lo que hice en 1974. Si el motivo entonces fue el tesorillo salmantino, hoy lo es básicamente la circulación monetaria en la ciudad de Clunia ${ }^{2}$.

Las lineas que siguen son datos y argumentos

' (f. M. P. (iarcia-Bellido, "Tesorillo salmantino de denarios ibéricos». Zephyrus 1974, pp. 379-395. Bibliografia sobre el tema: pro la localización de sckobirikes en la Meseta norte: J. Untermann. Monumenta Linguarum Hispanicarum, I. I. (cit. MLH) Weisbaden 1975, p. 316, (f). quien la situaria en el alto Ebro (opinión expresada ya en «Zur (iruppierung der hispanischen "Reitermünzen", $M M$ 1964, p. 141s. y con dudas en p. 148; Martin Valls, cf. addendum; p. 450s; L. Villaronga, "Sobre la localización de Segobriga». Gaceta Numismática 1978, pp 13-17; contra esa localización norteña y en pro de su situación en (abeza de Griego: M. Almagro Basch, Segobriga I. Los textos escritos.. $E A E$ 123, Madrid 1983, pp. 168-17:. M. Almagro-Gorbea \& A Lorrio, Segobriga III. La muralla norte y la puerta principal. Campañas 1986-1987. Cuenca 1989, esp. pp. 189-192. M. Almagro-Gorbea, "La romanización de Segobriga», Dialoghi di Archeologia 1992, pp. 275-288. El cuadro y mapa que van al final del trabajo son parte esencial de la argumentación. Varios datos bibliográficos sobre hallazgos se los debo a C'ruces Bláquez, al igual que a Ignacio Barandiarản, Ricardo Martin Valls, Luis Caballero y Angel lisparza, reciban desde aqui mi agradecimiento.

2 J. M. Gurt, Clunia III. Hallazgos monetaries, EAE, 145, Madrid 1985, esp. pp. 26-62. Recopilación importante donde se cartografian y estudian todas las piezas procedentes del habitat. 
recogidos y aplicados según una metodologia ya clásica en numismática, basada en los estudios de dispersión monetaria. Gracias a ellos podemos asegurar que las cecas suelen hallarse en el epicentro de la dispersión de sus monedas, de ahi la importancia de la recogida de los hallazgos y de su plasmación cartográfica. Esta metodologia la utilizó ya Zobel para adjudicar a España importantes series de moneda cartaginesa, en contra de la común opinión europea de entonces que las creía africanas. Es cierto que los datos de los hallazgos fueron tan contundentes, que tras conocer los argumentos de Zobel la ciencia internacional aceptó la existencia de una moneda hispano-cartaginesa, indudablemente bárquida, que venia a certificar los datos de las fuentes literarias sobre la fuerza politica de esa familia en el «reino» hispano ${ }^{3}$. Más tarde Delgado la aplica a muchas otras cecas béticas, y con ellos, no sólo numismatas, sino filólogos, arqueológos e historiadores la han empleado para cartografiar datos materiales que permitan, por aproximación o extensión, localizar talleres of fenómenos culturales. Es un método bien contrastado, cuyos resultados han sido óptimos en muchos casos e imprescindible y exclusivo en aquéllos en que el material arqueológico es único - monedas en nuestro caso.

Quiero adelantar al lector alguna de las conclusiones de este trabajo para sensibilizar su criterio sobre los datos recogidos, lo que me evitará después reiteraciones e insistencias: es posible, como entonces apunté, que la Segobrix republicana estuviese en los aledaños de Palenzuela, Clunia, Uxama, Roa, etc., pues la circulación de moneda republicana de śekobirikes, que fechamos ya en los finales del siglo $\|$ y en el primer cuarto del siglo I a.d.C., fue aqui fluida y mayoritaria, $y$ sin embargo su total ausencia en los tesoros o yacimientos cercanos a Cabeza de Griego muestran que su ceca no pudo hallarse en esas latitudes (figuras 8-10). Hoy -1986opino que esa ciudad republicana de la Celtiberia norte, quizás fuese arrasada por los romanos tras las guerras sertorianas o durante ellas, $y$ a mi entender, y esto es lo más conflictivo, trasladada su población al enclave que hoy conocemos en Cabeza de Griego, en cuyos aledaños sí se halla moneda

J. Zobel de Zangroniz. «Über einem bei Cartagena gemachten Fund spanish-phönikischer Silbermünzen». Monatsherichte der kaiserlich Akademie der Wissenschaften zu Berlin, Berlin 1963. En alguna bibliografia reciente se le ha adjudicado a E. S. G. Robinson, cf. M. Crawford, Coinage and money under the Roman Republic, Londres 1985, p. 89 , n. 9. imperial de SEGOBRIGA - nunca de sekohirikescon tipos que realmente son una continuacion de los estampados en su moneda republicana, sirviendo de enlace tipológico entre ambas series la escasa emisión con leyenda SEGOBRIS y la transicional con cabeza augústea (figuras 1-4). La serie con leyenda SEGOBRIS no es fácil de situar, ni en tiempo ni en espacio, porque no contamos con ningún hallazgo de procedencia conocida, pero hay que recalcar, según opinó Villaronga en su dia, la gran similitud con las monedas de Clounioq (figura 5), lo que podria indicar que todavía se emitio en Celtiberia, paralelismo que ya se había dado con los denarios de śekobirikes tan similares a los de kolounioku, haciéndonos suponer que estas dos cecas republicanas hubieron de hallarse muy próximas. Pero es cierto, como ya vió P. Beltrán y hoy insiste Villaronga, que también existe un parecido grande con la últimas serie de kontebakom kaŕbika (figura 6). ciudad que situamos en Fosos de Bayona. Sobre estos datos volveré más abajo.

\section{SEKOBIŔIKES}

Como he dicho, los nuevos hallazgos de moneda de śekobirikes refuerzan la opinión que expresé en 1974, y a modo de anexo al repertorio que ofreci entonces, añado ahora nuevas piezas del viejo tesorillo de denarios celtibéricos aparecido en Roa, localizadas y publicadas por J. D. Sacristán ${ }^{4}$. Parece ser que doce denarios más de śekobiŕikes se montaron como pulseras poco después del hallazgo y otras monedas ibéricas se conservaban en el lugar cf. figura 10, hallazgo 43 . Si con los viejos datos Segobrix poseía un 55,79 por 100 del tesorillo, ahora tiene el 54,60 por 100 del conjunto. El mismo trabajo de Sacristán da noticias de los despojos de otro tesorillo procedente de la zona, restos que como ha demostrado el conjunto anterior y estudios teóricos sobre el problema pueden, en la inmensa mayoría de los casos, ser una muestra muy digna del

\footnotetext{
+La Edad del hierro en el valle medio del Duero, Ruuda (Roa. Burgos), Valladolid 1986, pp. 212-216. Del tesorillo conocemos ahora 163 monedas, de ellas 89 denarios de śekobirikes, 57 de turiaso, 7 de árekorata, 5 de arsaos, 3 de bolśkan y 2 de baskunes. En página 216 dice: "composición tipica de los conjuntos aparecidos en el interior de la Meseta correspondientes a estos años (sertorianos), con una mayoria de los denarios de sekobirikes". Otros datos reiterativos son los procedentes del tesoro de Palencia con 12 denarios ibéricos, de los que 9 son de sekohirikes. dos de turiaso y I de arsaos.
} 


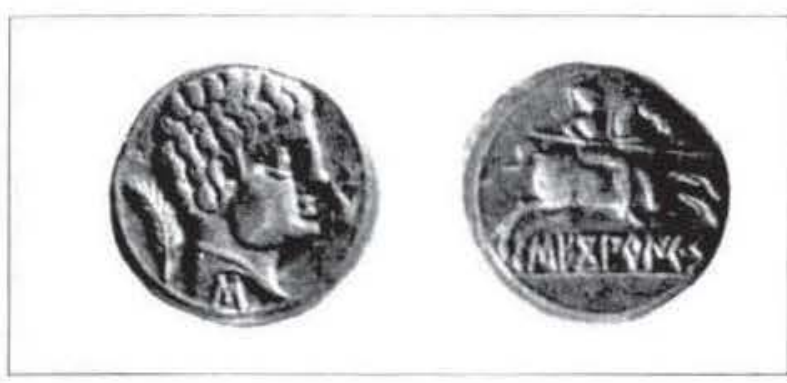

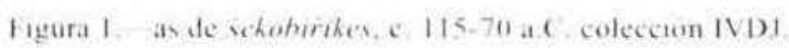

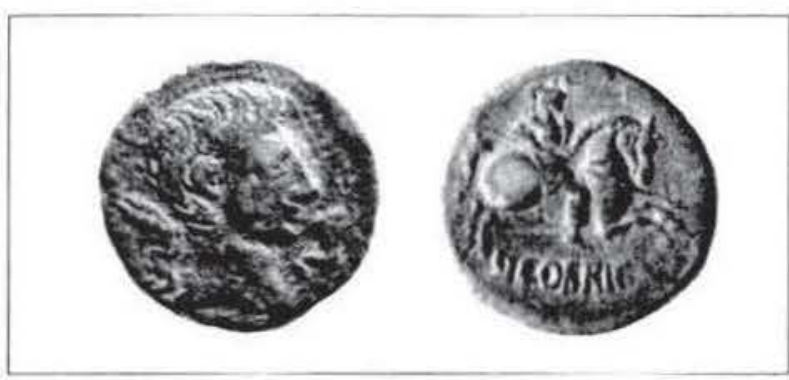

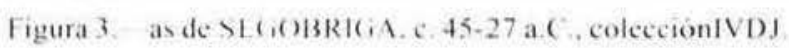

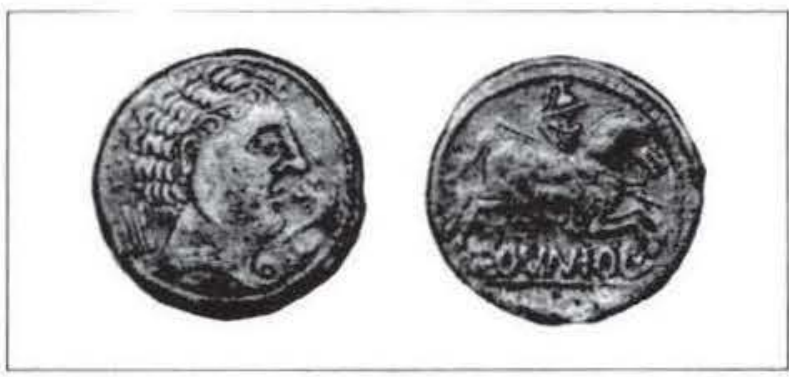

Figura 5. as de ( LOVNIOQ, e, 75-45 a. C... coleccion IVDJ.

total. Los restos son escasos, con un total de 24 monedas, de las que 14 denarios son de sekobirikes. 9 de baskunes y I de bolskan. dándo a śekobirikes efectivamente un porcentaje del 58.33 por 100 , algo superior al anterior conjunto. Constatamos, una vez más, que la composición es homogénea y constante, con una mayoritaria proporción de moneda de sekobirikes en todos los hallazgos monetales de esta zona de la Celtiberia. Porcentaje similar, de un 53,33 por 100 , proporciona el de Filipenses $\left(n^{\circ} 36\right)$ de Palencia, y muy superior el de Cerro de Miranda $\left(\mathrm{n}^{\circ} 13\right)$ con un 75 por 100.

Muy explicitos son también los datos que proporcionan los tres tesoros de Padilla de Duero $\left(\mathrm{n}^{\circ} 35\right)$ en curso de publicación. Dos de ellos contenian monedas, cuyo total, a juzgar por el catálogo de la exposición, es de 72 piezas, de las que 34 son de sekobirikes, 26 de turiaso, 6 de arekoratas y 6 de arsaos. Estas cifras dan un 36 por 100 a seko-

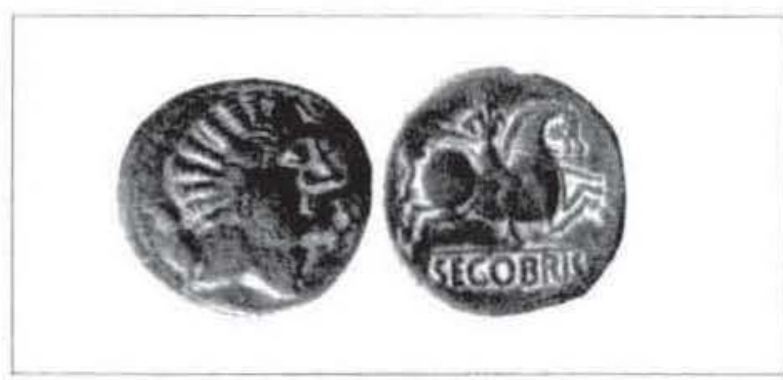

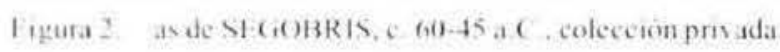

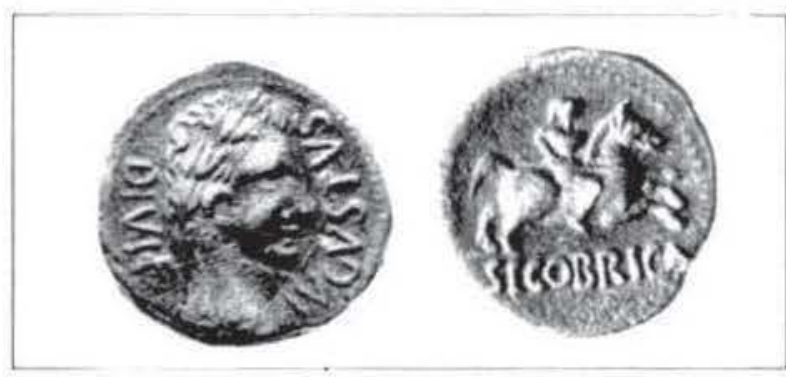

Figurat, as de StGOBRIGiA, c, 27.2 a. C, coleccion IVD)

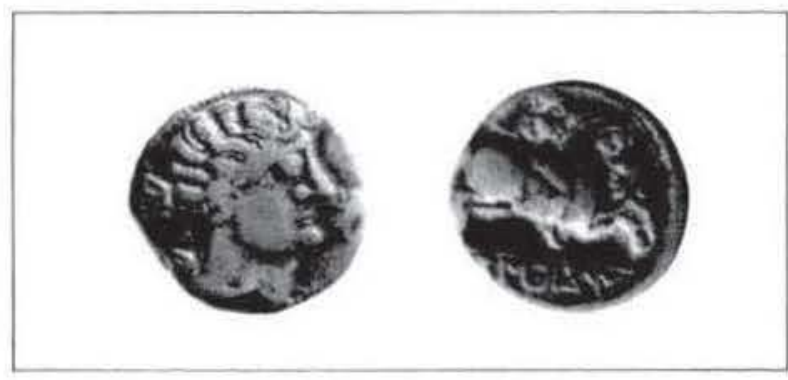

Figura 6. as de kontebahom karbika, c, 72-60, colección IVDJ.

birikes, porcentaje algo más bajo que el que proporcionan los hallazgos de Roas

Más datos, pobres pero reiterativos, recogemos

'Como no tengo sino los datos de la totalidad. los incluyo en un solo conjunto en espera de la publicacion precisa. El Tesorillo de Padilla I. publicado por T. Mananes. Arqueologia V́allisoletana 11. Valladolid 1983. pp. 152-157. es inutilizable para estos efectos porque aunque dice en p. 152 que contiene denarios ibéricos. luego no los recoge sino como alusión lateral en p. 157 y 58 . sin que quede claro si formaban parte del teso. ro sean los que fueren. o si son de otros conjuntos que el editor utiliza como paralelos. G. Delibes y A. Esparza, "L Los tesoros pre-romanos de la Meseta Norte y la orfebreria celtibérican en El oro en la Expaña Pre-romana. Revista Arqueologia 1989. p. I10, donde recogen tres diferentes hallazgos en Padilla. dos de ellos todavia ineditos. La bibliografia que sigue la debo al Prof. Angel Esparza: C. Sanz Minguezet alii. Padilla de Duero Evcavaciones arqueologicas 1985-89. Catálogo de la exposición de Peñafiel. Agosto 1989. Valladolid 1989, p. 15. Demasiado tarde para ser incorporada en este trabajo me llega la nueva y detallada publicación de estos tesoros, $\mathrm{cf}$. Addendum. 
de la región soriana y de la burgalesa donde la moneda de sekohirities es acompañada de la de turiasoy de arekorata según el patrón habitual ", extendiendo su presencia hacia el noroeste como demuestran los hallazgos de León, en Cacabelos, San Martin de Torres. Morgovejo y Lancia ${ }^{-}$. Y sin embargo es en esta /ona norte, cercana a cántabros y astures, donde las monedas de sekohirikes aparecen solas y en abundancia con exclusión de los denarios de otras cecas celtibéricas, como por ejemplo en Somiedo (sur de Oviedo) ${ }^{x}$, al igual que ocurre en los dos aportes de Amaya, uno de ellos de 40 denarios, más los frecuentes, aunque escasos en unidades, de las cuencas altas del Ebro y el Pisuerga, datos todos ellos que podrian indicar una situación más norteña de la Segobrix republicana que la que yo he propuesto, y que la del resto de las cecas celtibéricas, monopolizando la circulación de sus monedas esas latitudes, y sin embargo, esta presencia tan al norte de moneda de sekohirikes puede deberse a la retención de monetario foraneo, reacción tipica de una economía que inicia su andadura en el uso de la moneda pero que sin embargo no la acuña, apropiándose del numerario más frecuente en la zona, aunque éste le sea ajeno. Y me inclino más bien hacia esta última opción, pues como veremos, los datos que ofrece la circulación de Clunia son muy explícitos como para alejar mucho Segobrix de ese territorio.

Dos tesorillos occidentales, el de Santana da Carnota y el de Arrabalde, ambos con joyería y con denario romano merecen ser comentados, aunque

\footnotetext{
" C. Garcia Merino, "Monedas inéditas procedentes de Uxama», BSAA, 1969, pp. 323-328, dice en p. 327: "las monedas más numerosas, como es habitual, son las de sckohirikesm.

7 T. Mañanes, Contribucion a la carta arqueolígica de la provincia de Leon. Centro de Estudios e Investigacion "San Isidoro", Leon 1977, en p. 333 dice: «til numerario iberico de la provincia de León es muy escaso. Hasta hoy la ceca más abundante es la de Segobirices". cf. aqui los hallazgos núms. 9, 17,18, 25, 32, 44 y los dos nuevos tesorillos de El castro del Chano (Peranzanes, León) no incluidos en el cuadro, donde en el primero de 17 denarios, 13 son de sekwhirikes, y uno de turiaso. bolskan, arsaos y arekoratas. El segundo tesorillo contiene 28 denarios de ellos 15 de sekobirikes. 9 de turiaso y 4 de holskan. cf. Guia del Museo de León Junta de Castilla y León, León 1993. p. 52. De nuevo observamos la clara mayoria de moneda de Segobrix.

^ J. L. Maya, «La cultura castreña asturiana», Lancia I, 1983. p. 221: "numerosas monedas iguales todas de segobirices».

"Para la circulación monetaria en el O. peninsular cf. C. Blázquez, La circulación monetaria en torno a la Via de la Plata desde sus inicios a los finales del reinado de Commodo. Tesis doctoral de la Universidad de Salamanca, 1993. Estos tesoros occidentales donde joyería y moneda - ésta a veces muy escasa-conviven, son un claro testimonio del infimo indice de monetización de la zona, donde la moneda, frecuentemente troceada, es atesorada como plata. Este mismo patrón lo tenemos en el
}

por otras razones". El portugués, fechable en las guerras sertorianas, contiene tan sólo dos monedas ibéricas, un denario de holskan y otro de sekohirikes, amén de 134 denarios romanos, cuya última pieza nos permite datarlo no mucho más tarde del -76 porque de ese año no hay sino una moneda, indicativo de ser emisión reciente, cuando las inmediatamente anteriores, del -79 son ya dos, y las más frecuentes del -80 son 4. patrón aplicable a un suministro fluido de numerario. Hay que tener en cuenta $\sin$ embargo, que a estas fechas corresponden las quejas que Pompeyo desde aqui eleva al Senado por carencia de moneda para la guerra peninsular - Salust, Hist. 2, 98 M, 2,9-, lo que podria indicar que, en este caso, el denario del -76 no proporciona una fecha inmediata al ocultamiento y si corresponde a la interrupción de entrada de numerario romano fresco; pero en Palenzuela si hay denario del -75 y del -74 , señal de que también durante estos años entró moneda romana en Hispania y que la ausencia en Santana puede deberse a que el escondite se efectuó poco después del $-76^{10}$. El tesoro portugués es muy complejo en su composición al contener tres torques de tipo ibérico, sin relación con los de la cultura castreña, lo que hace pensar en la estancia del dueño en el este peninsular, diez pendientes del tipo Ib de Raddatz, quien sólo conocia el ejemplar de Santiago de la Espada (Jaén) pero de los que ahora tenemos una alta concentración en el valle bajo del Tajo donde también se localiza nuestro hallazgo, moneda celtibérica y abundante moneda romana que viene a fechar éste, amén de los otros escondrijos cercanos que por contener sólo joyeria ofrecian cronologías muy laxas, dentro de las guerras sertoria-

levante y sur peninsular para fechas mucho más tempranas ss. III-II-. pero es impensable sin embargo en tiempos augústeos. cf. mi articulo «tl proceso de monetización en el levante y sur hispánico durante la Segunda Guerra Púnica», Lengua y' cultura en la Hispania prerromana. Actas del V Coloquio sobre lenguas y culturas prerwomanas, Colonia 1989. Salamanca 1993. pp. 334-338. Iste cambio en el tipo de atesoramiento en Levante es un buen indice de que aquellos mixtos son también acumulación de capital y no escondrijos de joyeros como se ha venido apoyando.

11 Palenzuela muestra un vacio monetal entre el 87 y el 75 / 74. vacio que no se corresponde en Santana, y por lo tanto no podemos decir que los tesoros celtibéricos de esas fechas corroboren de carencia total de moneda romana durante varios años. según narran las quejas de Pompeyo. Volviendo al tesoro de Palenzuela. hay un dato importante que conviene tener en cuen. ta: su último denario romano-RRC 397 es fechado ahora por Ch. Hersh y A. Walker en el - 71 («The Mesagne hoard" MN 1984, 103-34, tabla 2, n* 13), lo que implicaria una cronologia post-sertoriana para el atesoramiento que parece incongruente en el contexto de Celtiberia. Creo pues que la fecha de Crawford es la correcta. 


\begin{tabular}{|c|c|c|c|c|}
\hline Barskunes & $6.81^{\circ} \circ$ & J) & Kelse & $4.54 \%$ \\
\hline Arsaos & $2.27 \%$ & K) & Sekaisa & $4,54 \%$ \\
\hline Bolskan & $2.27 \%$ & L) & Bilbilis & $6.81 \%$ \\
\hline Kaiskata & $4.54 \%$ & M) & Belikio & $4.54 \%$ \\
\hline Turiasu & $4.54 \%$ & (O) & Kese & $4,54 \%$ \\
\hline Karaues & $2.270_{0}^{\circ}$ & P) & Arse & $2,27 \%$ \\
\hline Arekoratas & $2.27 \%$ & Q) & Valentia & $2.27 \%$ \\
\hline Saltuic & $2.27 \%$ & R) & Saiti & $2.27 \%$ \\
\hline Arkailikos & $4.54^{\circ} \circ$ & S) & $\begin{array}{l}\text { Sekobirikes } \\
\text { clouniog }\end{array}$ & $\begin{array}{r}13,63 \% \\
6,81 \%\end{array}$ \\
\hline
\end{tabular}

Figura 7. Porcentajes de moneda hispana-republicana hallada en el yacimiento imperial de ( lunia moneda residual . segun J.M. (iurt. p. 29 (cf, 1n. 2),

nas ${ }^{11}$, lo que nos hace plantearnos si el territorio afectado por la penetración de tropa romana no fue mucho más extenso que lo que creiamos, y si la presencia del ejército se limitó realmente a las vias de conexión entre Extremadura y Celtiberia. Ello no parece ser cierto pues el tesorillo de Santana se integra en el jalón de testimonios que desde los castra Caecilia hasta Palenzuela fue dejando la tropa romana en las guerras sertorianas, piénsese por ejemplo en los tesoros de Monroy, Valdesalor, Cabeça da Corte, etc. ${ }^{12}$. Precisamente la disminución del porcentaje de moneda romana a medida que nos internamos en el espacio celtibérico y su substitución por denario ibérico es lo que nos hace pensar que la tropa romana, ahi, fue en casos pagada con plata indígena. El último hito en este jalón seria el tesoro de Barcus, en el Pirineo francés, escondido posiblemente por un soldado en su marcha anual para invernar en Gallia.

En Arrabalde (Zamora), tesoro mixto con abundante joyeria de tipo castreño, es decir local, ocultado en ocasión de la guerras cántabras como su situación y los denarios de Marco Antonio y César

1t J. R.Viegas y R. Parreira, «Der Schatzfunde von Santana da Carnota», MM 1984, pp. 79-91. fig. 2. Los AA. dan una cronologia al tesoro post -72 por el denario de bolskun que consideran la pieza más joven del conjunto, y sin embargo el denario pertenece al grupo I de G. K. Jenkins ( $₫$ A Celtiberian Hoard from Granada», $N H 14,7,1958$, pp. 135-146) con cuyo $n^{\circ} 7$ de Lảm. I comparte el mismo cuño de anverso. L. Villaronga ( Ordenación y cronologia de los denarios de la Celtiberian, GN 3-4, 1987. p. 9 ss) ha antepuesto un grupo más antiguo, dando una cronologia a su Grupo II, al que pertenece el denario de Santana, entre el -104 y el -92 como los hallados en Salvacanete, aunque perdurarón en circulación todavia en tiempos sertorianos, como vemos en el tesorillo de Salamanca. Es claro que una cronologia para el tesoro post. -72 , sólo por la pieza de bolíkin. no debe ser correcta.

12 C. Blázquez, «Tesorillos de moneda republicana en la peninsula ibérica. Addenda a Roman Republican Coin Hoards", Acta Numismática 18,1988 , pp. 124-26. muestran ${ }^{13}$, el patrón de cecas es similar al de Salamanca - arsaos, bolskan, sekobirikes y turiasoaunque falta aíekoiata, pero el porcentaje de presencia es distinto, pues turiaso y no sekobirikes es la ceca más representada. El alto número aqui de moneda de IIiriaso y la falta de la de aiekoíata, podrian ser un buen testimonio de la modernidad de unas y de la antigüedad de otras monedas como opina Villaronga ${ }^{14}$ Pero el tesoro reitera lo comentado para esta zona más arriba en los de Somiedo, Lancia, Bierzo etc.

\section{CLUNIA Y SEEKOBIŔIKES}

$\mathrm{Y}$ sin embargo, los datos más interesantes de circulación nos los proporciona el yacimiento de Clunia por formar un conjunto con sus coordenadas espacio-tiempo muy bien delimitado, y por tener tras de sí muchos años de excavación y recogida de materiales, lo que supone contar con un porcentaje de documentación alto y fiel a la hora de estadisticas. J. M. Gurt ha hecho el estudio de todas las monedas halladas en el habitat, que como sabemos es de época imperial, sin que se haya localizado todavia la ciudad indigena, supuestamente sita en un cerro cercano que, sin embargo, no proporciona materia-

\footnotetext{
13 Para las monedas V. Sánchez de Arza, "Las monedas del tesoro de Arrabaldem. Numisma 1984, pp. 51-74. Para el conjunto cf. R. Martin Valls y (i. Delibes, El tesoro de Arrabulde y st entorno) histórico (Ciuia de la exposición) Zamora 1982: A. Esparza, Los castros de la Edad del Hierro del NO de Zamora, Zamora 1986, p. 37 y 376 . Su ocultamiento pertenece al mismo horizonte que el tesorillo de Ramallas con plata augústea y de Carisius: H. Mattingly, «A hoard of Roman denarii from Spain (Ramallas), NC XV. 1935, pp. 289-90; A. Esparza, "Joyas celtibéricas de Zamora en el Museo Británico, BSAA 1983, pp. 38-45.

it L. Villaronga, op, cit. (n. 11) pp. 9-21, considera que la mayoria de los denarios de turiaso y todos los de sekohirikes se acuñaron durante las guerras sertorianas, 80-72. Sin embarge los de aŕekorata si son, según su opinión, más tempranos.
} 


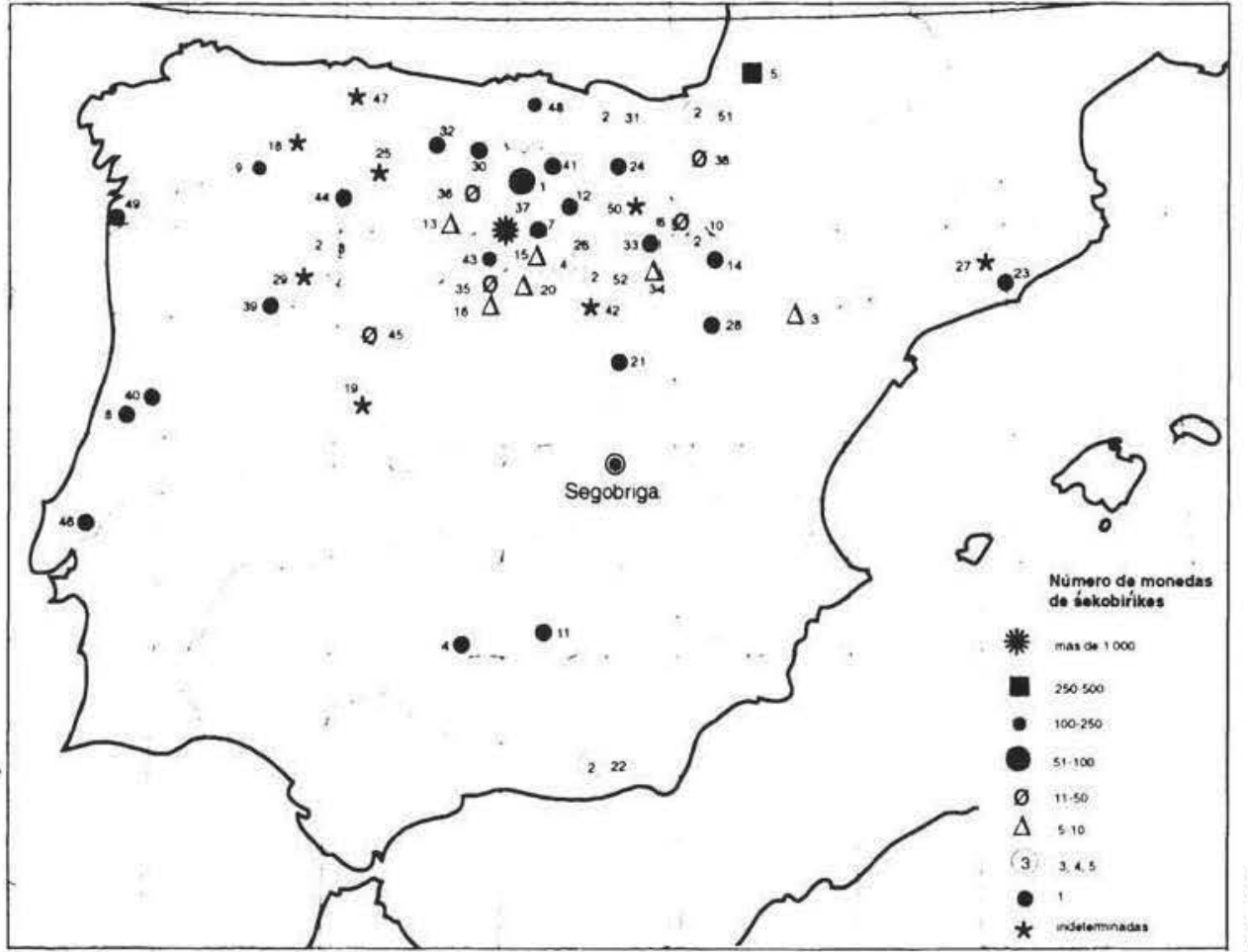

ligura 8. Mapa de los hallazgos de moneda de whobirikes. les ni suficientes ni específicos que permitan llamarla klounia, nombre que se deduce de sus monedas republicanas con leyenda kolounioku. Aunque la ciudad de klounia acuñó en época republicana, la presencia de su moneda y la del resto de las acuñaciones ibéricas debe juzgarse en este yacimiento como muestra residual pues, como dije, la ciudad excavada es la imperial. De toda esta moneda ibérica: edetana, sedetana, vascona, del Jalón y celtibéricaes lógicamente éste último grupo, por cercano, el más abundante, pero de entre las ciudades celtibéricas es sekobirikes con un 42,85 por 100 la ceca mejor representada, seguida por la propia klounia con 21,42 por 100 , hecho muy comprensible porque las emisiones republicanas de esta ceca son extraordinariamente escasas. De toda la moneda "ibérica» circulante en la ciudad en estas fechas, śekobirikes tiene en Clunia el porcentaje más alto, un 13,63 por 100 y kolounioku un 6,81 por 100 , como podemos observar en el cuadro de J. M. Gurt, reproducido en mi figura 7. La alta presencia de śekobiríkes en Clunia es puesta en relación por el autor con los datos que proporciona Uxama, naturalmente semejantes, e insiste en que es el dato constante en los hallazgos de la Meseta ${ }^{15}$. En contrapartida a esta mayoritaria abundancia de moneda de śekobirikes debo decir

\footnotetext{
${ }^{15}$ Mi fig. 7 es el cuadro de su pág. 29.
}

que en Clunia no ha aparecido ni una sola muneda de SEGOBRIGA. De la etapa pre-augústea, que Gurt hace arrancar del -50 , el A. recoge once monedas - p. 34-, que sin embargo no se desglosan aunque por el mapa sabemos que proceden de Emporion, Clunia ${ }^{16}$, Colonia Lepida, Ebusus y Cástulo. No hay moneda de SEGOBRIS ${ }^{17}$, ni de la SEGOBRIGA transicional, augústea o tiberiana - teniendo este periodo en la ciudad de Clunia el mayor porcentaje de moneda año-, ni tampoco de Caligula. Todo ello hace aconsejable buscar la situación de la Segobriga imperial en otro lugar de Hispania, muy probablemente, como se ha venido siempre defendiendo, en Cabeza de Griego, y plantearse si las acuñaciones de śekobirikes y las de SEGOBRIGA no corresponden a dos enclaves distintos de una misma entidad politica ${ }^{1 \times}$.

it En el inventario se consignan 3 piezas que se dan como con signos ibéricos en anv, y no son sino dos barras verticales con valor numeral posiblemente, corresponden a Vives 163,1 y 173,10 , todas con leyenda latina CLOVNIOQ.

${ }_{17}$ Asi es como aparece escrito el topónimo en la escasa emisión transicional a Augusto, y sin embargo los indigenas debieron pronunciar Segobrix, lectura ya defendida por A. Tovar, cf. J. Untermann, MLH, p. 316.

${ }^{1 \times}$ Un dato más pone en intima relación las piezas de sekobirikes con Clunia: sabemos que los bronces clunienses de Tiberio están en su práctica totalidad contramarcados con cabeza o cuerpo de jabali en reverso y anverso respectivamente. Estas dos contramarcas son exclusivas de Clunia, con dos únicas excepciones 


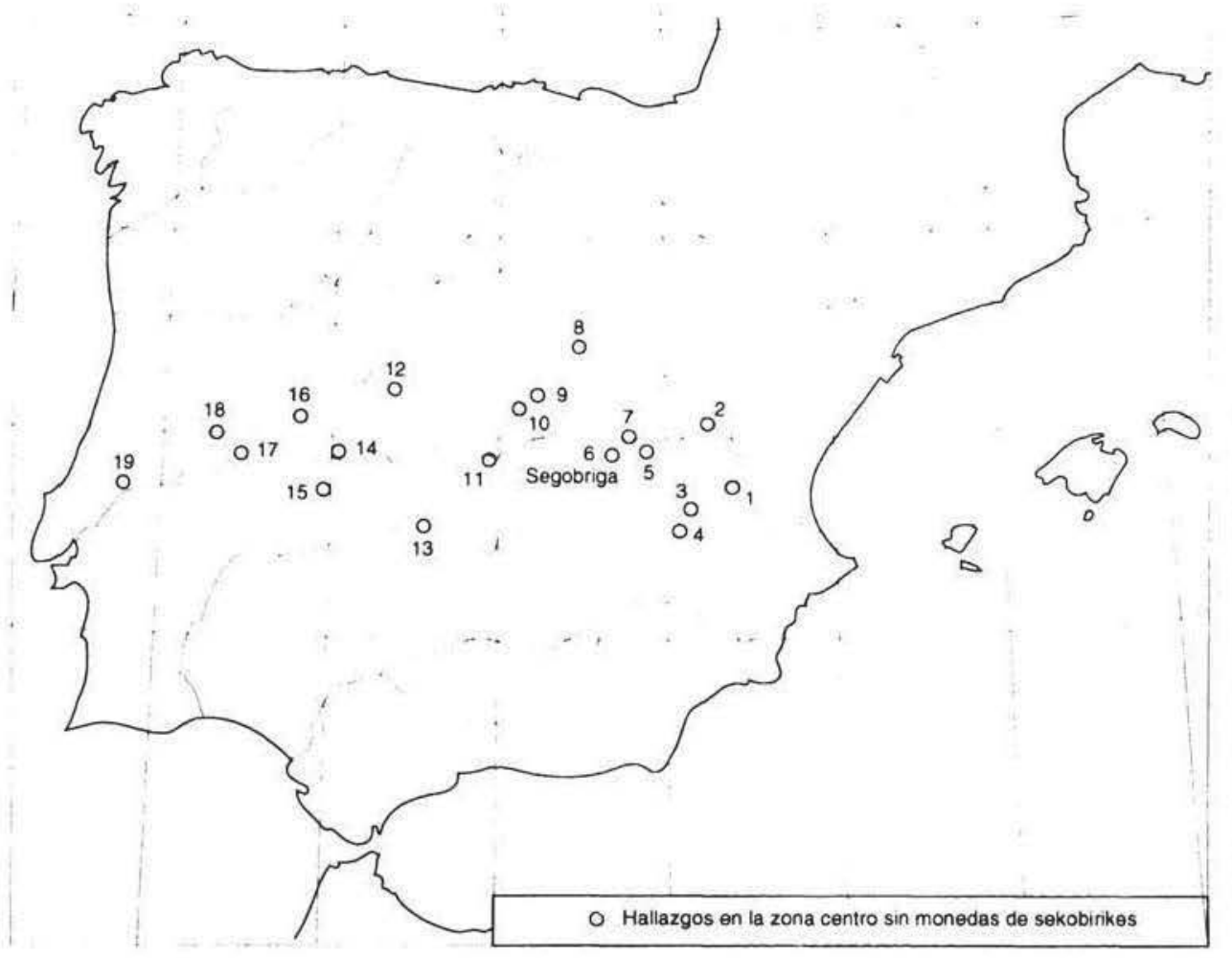

Tigura 9.- Mapa de las ausencias de moneda de sekohirikes en los hallazgos de la zona centro: I Caudete de las Fuentes: 2 Salvacañete: 3 Madrigueras: 4 Motilla del Palancar; 5 alrededores de Cuenca; 6 Cabeza de Griego: 7 Fosos de Bayona: 8 alrededores de Sigüenza; 9 Alcalá de Henares: 10 Madrid: 11 Toledo; 12 Puente del Congosto: 13 Tamurejo: 14 Caparra; 15 Cáceres el Viejo: 16 Gata; 17 Idanha-a-Velha: 18 Alcaide; 19 Charneca.

La alta presencia que comentábamos de moneda de śekobirikes en la Meseta norte se ve correspondida con su total ausencia en los yacimientos de Cuenca (figura 9). Recordemos que las excavaciones en Cabeza de Griego no han proporcionado ni una sola moneda de śekobirikes, aunque sí de Segobriga ${ }^{19}$. Es cierto que los materiales mas antiguos

por ahora, una pieza de Calagurris del IVDJ (M. P. Garcia-Bellido y C. Blázquez, "Contramarcas y monedas celtibéricas en el Instituto Valencia de Don Juán", Acta Numismática, 18. 1988, p. 65), lo que no es extraño visto el porcentaje de sus monedas en el yacimiento de Clunia para época de Tiberio (Gurt. cit. n.2 p. 56 ). La otra moneda contramarcada es más explicita y se trata de un as de sekobirikes, muy desgastado, contramarcado con un jabali $(i)$ en reverso. Ello quiere decir que en época tiberiana todavia circulaba en Clunia abundante moneda de sekobirikes. hecho que constata Gurt al hablar de moneda residual republicana en época imperial, y que de ella se eligió, a falta una mayor abundancia de la cluniense contemporánea, otra bien aceptada por los usuarios por estar habituados a ella, una de sekohirikes. Sin embargo esta contramarca la conocemos sólo por una impronta, lo que aconseja tomar el dato con cierta cautela, (cf. M. P. Garcia-Bellido y M. Garcia de Figuerola, Album de la colección Sánchez de la Cotera, Madrid 1986, $\mathrm{n}^{\circ} 1782$.

${ }^{19}$ A pesar de que el material numismático en Cabeza de Griego no puede ser más pobre, sólo tres monedas publicadas, dos de Segobriga y una imperial de Commodo, es evidente la «mayoria» de piezas de Segobriga, cf. H. Losada y R. Donoso, Excavaciones en Segohriga, EAE $\mathrm{n}^{\circ} 43,1965$, pp. II, 50 y 53. En las campañas de 1986-1987 publicadas en op.cit. (n.1) han aparecido 15 monedas romanas que corren desde el c. 72 a.C. y el 162 d.C., ninguna de śekobirikes, pero si 2 de Segobriga. salidos alli a luz en estratos arqueológicos son de época bajo-republicana: cerámicas de barniz negro que M. Almagro - p. 192 - fecharía en tiempos postsertorianos o cesarianos, al igual que la terra sigillata itálica. Pero hay que puntualizar, como hace él, que los materiales más precisos para la cronologia son allí los numismáticos, y ellos evidencian que todavia no se ha dado con la ciudad republicana, pero ¿es que la hubo?, y ¿desde cuándo? Sería de esperar que en una circulación monetaria del 72 al 45 a.C. constatada en el yacimiento por las piezas de Bilbilis y Celsa, estuviesen presentes las monedas de śekobirikes, si es que aquélla había sido su ceca. Recuérdese que sin embargo en Clunia, donde el yacimiento excavado es el imperial, predominan los bronces de śekobirikes dentro de la circulación residual.

Más datos ex absentia proceden de la provincia de Cuenca (figura 9). Del yacimiento de Villasviejas (Fosos de Bayona), lindante con Cabeza de Griego, son las monedas ibero-romanas publicadas por C. Alfaro entre las que una vez más faltan las de śekobirikes. El yacimiento tuvo larga vida, desde el Bronce final hasta las guerras sertorianas, a juzgar por las monedas ${ }^{20}$. Las hay hispano-cartaginesas,

${ }^{20} \mathrm{C}$. Alfaro, "Hallazgos monetarios en "Foso de Bayona", Villasviejas (Cuenca). Rev. Cuenca, 19-20, 1982, pp. 79-84. La A. opina que el final del habitat debe fecharse con las guerras sertorianas como la presencia de moneda de holskan. hilbilis y 
de libusus, de kontehakom, kasitilo, sekaisa, ikalesken. bolskan. hilhilis y dos de Roma. Entre esta variada presencia de monedas ni una sola es de sekohirikes. como tampoco las hay en los otros hallazgos de la zona centro que estudié con este propósito en el $74 \%$. Es un dato ex ahsentia que por reiterativo y nuclear debe tenerse muy en cuenta. Tampoco aparecen sus monedas en el nuevo hallazgo de Almadenejos (Ciudad Real) fechado su cierre en post. 100 que, aunque con una amplia mayoria de denario romano también lo hay de ikulesken y ursuos 2 .

Entremos ahora en los datos que proporcionan los hallazgos de moneda con epigrafe latino SEGOBRIGA (figura 4), pero antes quisiera hacer ciertas consideraciones numismáticas que creo son importantes al respecto. Las acunaciones con leyendas celtibéricas (figura 1), que ya comentamos en el 74 cuán semejantes eran a las piezas de sekotias y aikuilikos (Langa de Duero y Burgo de Osma, u Osma), son seguidas por los ases con leyenda latina SEGOBRIS (figura 2), cuya semejanza a las piezas de Clunia con leyenda Clounioq es extraordinaria (figura 5), sugiriendo que ambas cecas, no sólo estaban muy cerca, sino que esas emisiones fueron coetáneas, lo cual es perfectamente posible a juzgar por su metrologia, módulos, etc. ${ }^{23}$. Pues bien, las emisiones pre-augústeas y augústeas (figuras 3 y 4 ) mantienen los mismos tipos que las de Segobris, indicando quizás que la ciudad politicamente fue la misma, y sin embargo sus circuitos no son coincidentes. Veamos algunos datos.

En la ciudad de Clunia, como ya hemos visto, la etapa que proporciona más modedas/año es la de Tiberio, fechas en la que la propia Clunia acuña bronce en abundancia y por tanto su porcentaje es el mayor respecto al resto de la circulación, un 74,66 por 100 , seguido de un 33,84 por 100 de Caesaraugusta ${ }^{24}$. El hecho de que Clunia acuñe sólo bajo Tiberio hay que relacionarlo sin duda con el asentamiento de tropas no muy lejos de alli o, si lejanas, alimentadas monetalmente por esta ceca que fue la más occidental ${ }^{25}$. Bajo Caligula la mayor parte de las cecas hispánicas suspenden sus acuñaciones y entre ellas está

kontehukom demuestran. Yo añado que también la hispano-latina de Cástulo núm. 7 debe fecharse c. 82. De recogidas posteriores en Fosos procede un centenar de piezas que comentamos infra.

${ }^{21}$ op. cit. (n.l) núm. $38-55$ de p. 384 y mapa.

22 A. Canto, "Sobre un hallazgo de denarios en Almadenejos (Ciudad Real), Oretum 3. 1987, pp. 293-317.

${ }^{23}$ La misma idea sugiere Villaronga y apoya la similitud tipológica y de factura entre los tres denarios que conocemos de kolounioku y los de sekobirikes.

${ }^{24}$ J. M. Gurt, op. cit. (n. 2) cuadro p. 44 y mapa p. 56.

${ }^{25}$ cf. M. P. Garcia-Bellido y C. Blázquez, op. cit. (n. 18).
Clunia, pero no Segobriga que sigue emitiendo. Durante esta etapa la alimentación del numerario de Clunia proviene en mayoria de la ceca más cercana, Caesaraugusta, cuyas monedas alcanzan el porcentaje más alto con un 66,66 por 100 , siguiéndolo Ereavica con un 33.33 por 100. En esta penuria de amonedación hispánica, en la que muy pocas cecas estan ya acuñando, seria de esperar la presencia de moneda de Segobriga que si acuña bajo Caligula. y sin embargo tampoco la hay. La ausencia total de numerario imperial segobrigense en Clunia presenta un claro contraste con la mayoritaria presencia, que hemos comentado, de piezas republicanas de sekohirikes en el mismo yacimiento. Si los métodos arqueológicos tradicionalmente empleados siguen siendo válidos, ambas emisiones no pueden proceder de una misma urbe.

\section{SEGOBRIGA}

Además del escaso numerario segobrigense hallado en las excavaciones de Cabeza de Griego citado más arriba, se ha publicado un tesorillo en bronce compuesto por 20 monedas de Segobriga y 1 de Turiaso procedente de Cabeza de Griego que, éste sí, proporciona una total mayoria de monedas segobrigenses imperiales, lo que no hace sino incidir en la disociación de los circuitos monetales de las dos etapas históricas de esta misma ciudad ${ }^{26}$. A parte de ellos, hay muy pocos hallazgos que constaten su presencia en otras regiones, a no ser zonas excesivamente alejadas de uno y otro emplazamiento como para poder dirimir con ello su ubicación. Moneda de Segobriga aparece en Levante, en el Noroeste y en Extremadura, pero en cantidades tan ralas que no implican ningún aporte valorable al problema. Levante es la zona de Hispania más temprana y densamente monetizada, lugar de embarque y desembarco de celtíberos mercenarios, más de tropa romana, más de equites y comerciantes itálicos, por lo que la presencia salpicada de una o dos monedas a lo largo del litoral o en la trascosta no es significativa en estudios especificos ${ }^{27}$.

26 J. M* Vidal, "Tesorillo de bronces hispano-latinos hallado en Segobriga (Cuenca), $A N$ 16, 1986, pp. 73-77; id. "Tesorillo de denarios hallados en Tiermes (Soria)", Gaceta numismática 89.1988 , p. 32 donde. llevado por estos mismos argumentos disocia, también él, las cecas republicana e imperial.

${ }^{27}$ Un estudio sobre la presencia en esta zona de moneda celtibérica presenté en "Moneda celtibérica fuera de la Celtiberia» Coloquio sobre Numismática en la C'eltiberia. Barcelona 1987. cuyo manuscrito no llegué a entregar. Practicamente todas las cecas celtibéricas presentan el mismo patrón en esa zona: presencia débil y salpicada. 


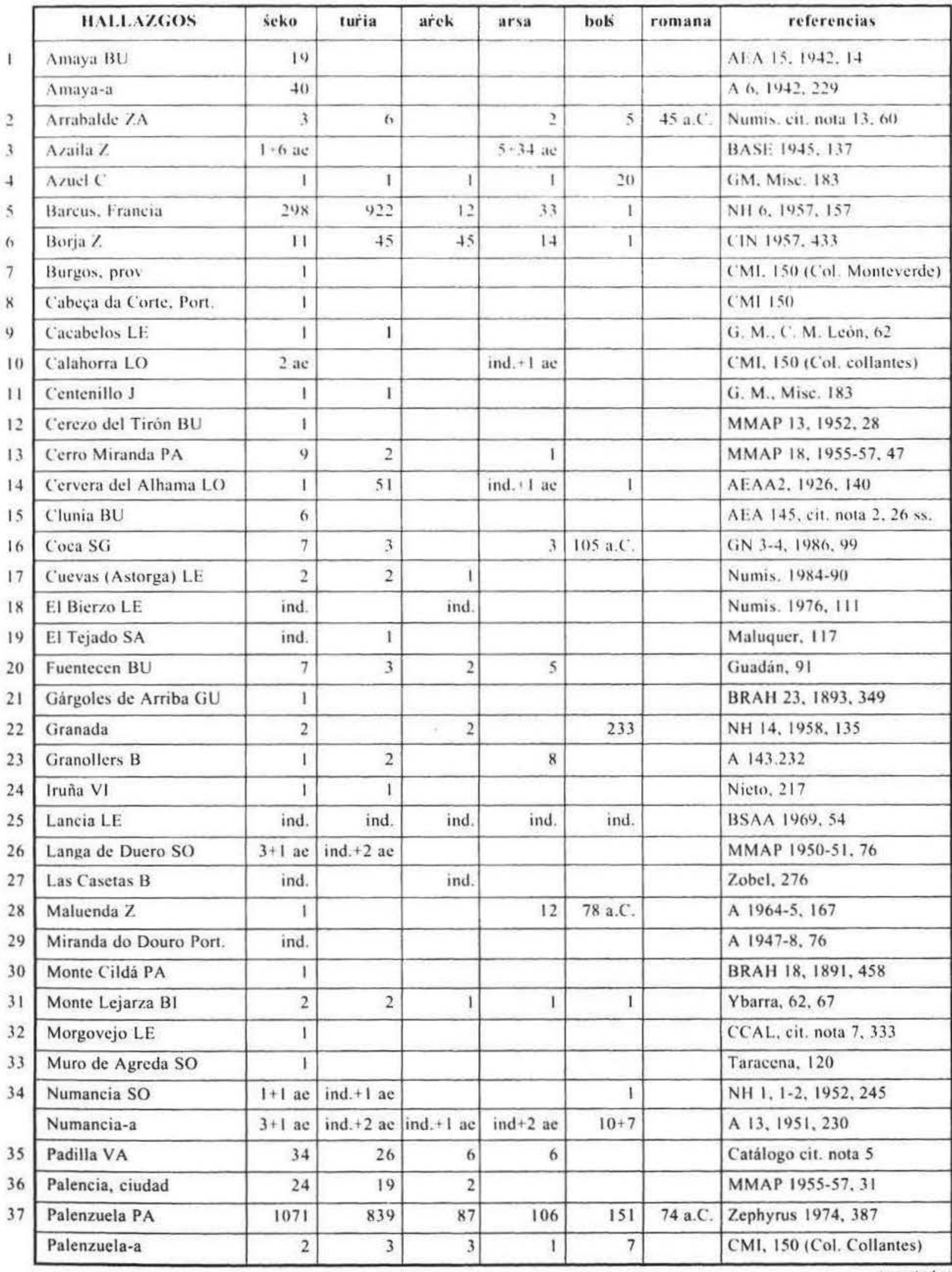

Figura 10.- Hallazgos de moneda de śekobirikes, con sólo las de triaso, aŕekoratas, arsaos, bolḱkan y romanas que acompañan. En general denario, cuando es ae va consignado. Los números corresponden al mapa. 


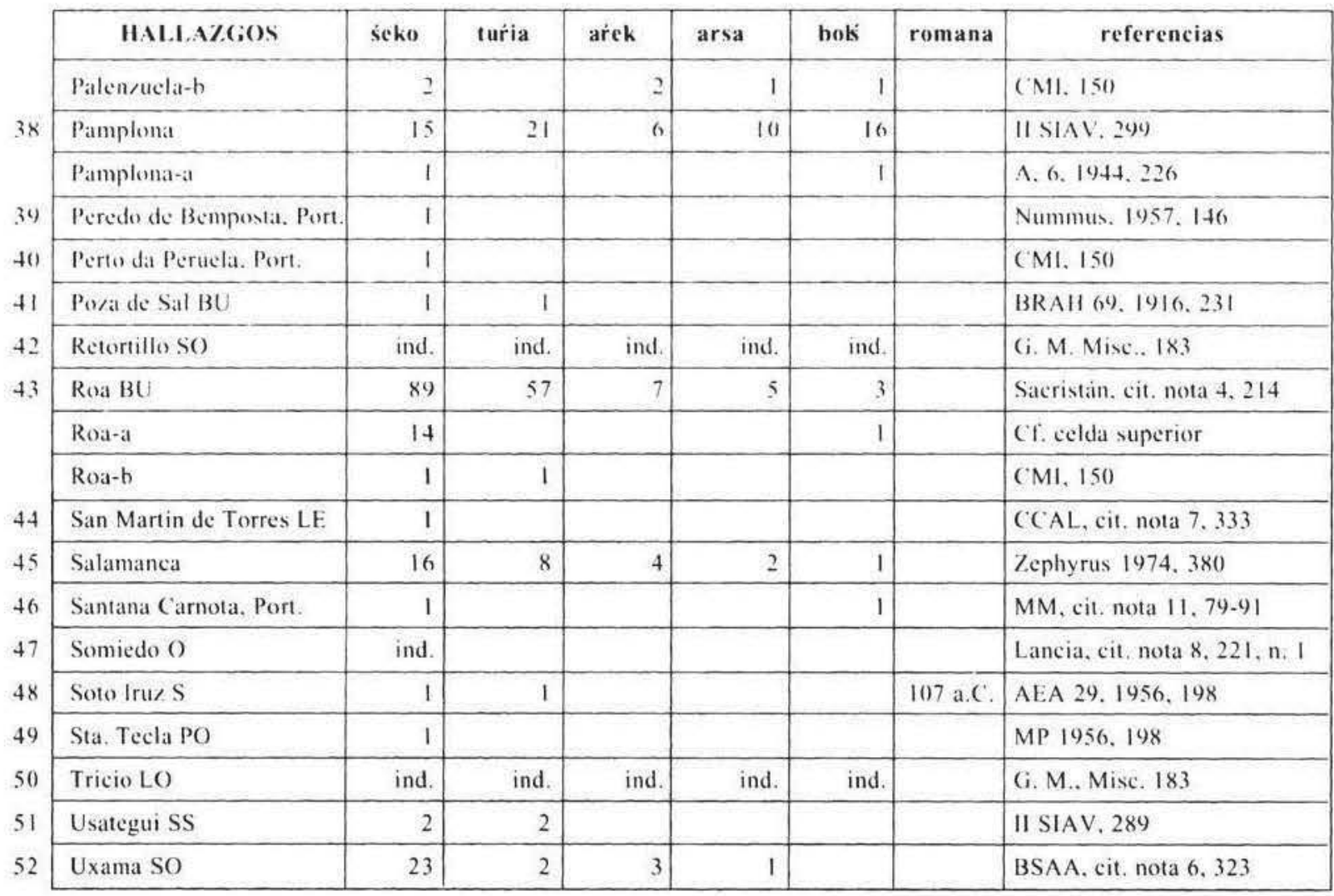

Figura 10.-- (Continuación)

A falta de estos testimonios podemos echar mano de otros, no tan explícitos, pero sí válidos: las contramarcas. Sabemos que el fenómeno del contramarcado se da por circuitos monetales, y que sólo se resellan aquellas monedas de la propia ceca donde el control se efectúa, o aquellas otras que por su frecuencia en ese circuito son aceptadas por el usuario y por la propia administración oficial como propias. El hecho es que habitualmente encontramos las mismas contramarcas sólo en monedas de una ceca o en las de procedencia muy cercana. Pues bien, Segobriga, cuyas monedas rara vez presentan contramarcas, repite los resellos de Carthagonova, y con menor frecuencia, pero también en algún caso, los de las cecas del Ebro, indicando su posición intermedia entre una y las otras. La contramarca I.S. se conoce sólo en tres ejemplares de Segobriga, uno de Tiberio y dos de Caligula ${ }^{2 x}$. Esta misma contramarca aparece sobre tres ejemplares de Carthagonova de Tiberio - Vives 132,1-que guarda el IVDJ.
Es decir que esta contramarca se la reparten Carthagonova y Segobriga en un 50 por 100 , y los mejores paralelos tipológicos para la grafia se encuentran en sellos de anforas Dressel 20 de época alto-imperial, procedentes de Villar de Brenes. Las contramarcas efectuadas dentro de sociedades de explotación son, como ya defendi en otro lugar, frecuentes y es lógico que en época de Caligula, en que las cecas del sur se han reducido a una, Acci, se produzca un vacuum monetal que atraiga el numerario más cercano, en este caso segobrigense y cartagenero, las otras dos cecas cercanas; existe sin embargo otra posibilidad que recoge $\mathrm{M}$. Almagro como verosimil, trasmitiendo una opinión de A. Balil, el que la contramarca estaria revalorizando la mone$\mathrm{da}$, un as, en un as y un semis ${ }^{29}$. La interpretación es plausible puesto que el descenso progresivo en el peso de las monedas de bronce conlleva su revalorización con el tiempo.

También la contramarca S.E. -Guadán, tipo

${ }^{2 k}$ A. de Guadán, «Tipologia de las contramarcas en la numismática ibero-romana», NII IX, 17, 1960, p. 96: M AlmagroGorbea, «Nuevo ejemplar de la contramarca I.S. sobre un as de Segobrigan, BSAA 43, 1977, pp. 99-108; M. P.Garcia-Bellido y C. Blázquez, op. cit. (n. 18), 
106 es comun en ambas cecas, indicando que sus numerarios entraban en áreas comunes de circulacion. (on las cecas del Fbro comparte Segobriga una de los resellos más frecuentes, Guadan tipo 24: ligadura de LA, que con pequeñas variantes aparecen en practicamente todas las cecas del Ebro. como Celsa, Calagurris, Bilbilis e incluso Ercavica. y que hemos puesto en relación posible con la Legio Alaudae to. Las contramarcas pues corroboran lo que los documentos epigráficos imperiales y algunos datos literarios atestiguan: la situación en la Meseta sur - probablemente en Cabeza de Griego - de la Segobriga imperial.

\section{SEGOBRIGA Y CONTREBIA CARBICA}

La ausencia de testimonios arqueológicos más antiguos de la fase post-sertoriana en Cabeza de Griego después de tantos años de excavación, obliga a plantearse la posibilidad de que alli no existiese una ciudad importante prerromana del calibre que hubo de constituir Segohrix republicana. Las monedas más antiguas halladas en Cabeza de Griego, vienen a confirmar los datos cerámicos y son: «...un as ibérico postsertoriano de Bilbilis, otro de Celsa bilingüe y un semis de Segobriga, todos ellos fechables en el segundo tercio del siglo । a.C.n ${ }^{3}$. Han aparecido, aunque siempre fuera de contexto estratigráfico. algunos materiales importados muy anteriores al momento que nos ocupa, como es el fragmento de ánfora ática de mediados del siglo $\mathrm{v}$, o los procedentes de las necrópolis excavadas a fines del siglo xıx en Uclés y Cabeza de Griego, donde en una urna de plomo y vidrio se halló, procedente seguramente de ésta última, un cáliz de figuras rojas. Pero estos materiales de importación lo son de prestigio y con ello objetos que pueden tardar en amortizarse siglos según sabemos, por ejemplo, de la Dama de Galera que, siendo del siglo viI, se entierra en el siglo IV. Por ello, la posible procedencia de Segobriga de objetos sueltos de importación no es argumento para llevar la historia de la ciudad muy atrás, al menos el de una ciudad de la importancia que hubo de tener la que acuñaba los denarios y bronces

\footnotetext{
30 $\mathrm{Si}$ la interpretación fuese correcta, el interés del dato es inmenso pues atestiguaria que de la legion $\mathrm{V}$ trasladada al Limes antes del -14 , quedan aqui algunas vexilationes. $\mathrm{E}: \mathrm{l}$ dato de que la legión utiliza el mismo sello en tejas de Novaesium lo publicaré en el trabajo sobre La moneda hispana en el Limes germảnico, en preparación. Cuadro de contramarcas en M. P. GarciaBellido y C. Blázquez, op. cit. (n. 18).

${ }^{31} \mathrm{M}$. Almagro opp. citt. (n. 1). La cita procede de "Interpretación...” p. 190.
}

republicanos, citada por las fuentes como objetivo a conquistar tanto por Viriato como por Pompeyo. según veremos. Pero muy cerca si existió una importante ciudad republicana, posiblemente (arbica. cuyas historia parece terminar cuando se inicia la de Segobriga.

Del yacimiento de Villasviejas (Fosos de Bayona) parecen proceder un centenar de monedas de las que tan sólo una es de sekobirikes mientras que treinta y cinco lo son de kontehakom kaihika, amén de que todas ellas son anteriores a Augusto, mostrando de manera segura que el yacimiento dejó de tener vida en época post-sertoriana. Los hallazgos monetales y las similitudes entre los tipos de las monedas de Carbica y de Segobriga (Vives 39.4 y 135,1 ) llevaron ya a $\mathrm{P}$. Beltrán a proponer una cercania y una secuencia en la vida de ambas cecas, semejanza que le valió para defender la situación de Segobriga en Cabeza de Griego ${ }^{32}$. Este argumento ha sido corroborado con otros de cariz histórico y arqueológico proporcionados por los excavadores de Fosos de Bayona: al igual que las monedas, las cerámicas dan un fecha de vida anterior a las guerras sertorianas, precisamente cuando Contrebia deja de ser citada en las fuentes y de emitir moneda. Más aún, el trazado de la via republicana que, sobre camino prerromano, corria desde Salduie hasta Carthagonova pasaba por Ercavica-Huete-Carrascosa-Fosos de Bayona-Villarejo de Fuentes pero «el trazado imperial rectifica y varia su desarrollo en función del auge de Segobriga y de la desaparición de Fosos de Bayona...". Todo ello ha sido considerado por los excavadores como «prueba del relevo de Segobriga con respecto a Contrebia, que por estas fechas (augústeas) ya habría sido destruida o abandonada»" ${ }^{3}$.

$\mathrm{L}$. Villaronga ha incidido recientemente sobre el tema proponiendo conclusiones similares a las de los excavadores de Fosos, basadas esencialmente en argumentos de metrología y estilo numismático. Pero Villaronga no propone una secuencia en la vida de dos ciudades distintas, sino un cambio de poblamiento de una misma ciudad, mientras sekobirikes desaparece en la Meseta norte sin continuidad monetal, Ercavica se convertiría en Segobriga. Un mismo taller habría acuñado las últimas monedas de kontebakom karbika y de inmediato las de SEGOBRIS, su estilo y su secuencia metrológica asi lo indicarian ${ }^{34}$.

\footnotetext{
12 P. Beltrản, "Segobriga», APL IV, 1953, p. 252.

"P. Mena et alii, "La ciudad de Fosos de Bayona... Datos de las dos últimas campañas de excavaciónn, I Congreso de Historia de Castilla La Mancha, vol. IV, pp. 183-187. Las citas proceden de p. 185 y 186 respectivamente.

${ }^{i 4} \mathrm{~L}$. Villaronga, "La qüestió de les seques de konterbia karbika i de Segobrigan, Empúries 48-50, pp. 364-366.
} 
Efectivamente. y como todos los argumentos expuestos muestran. Fosos de Bayona y Cabeza de Griego. muy posiblemente Contrebia Carbica y la Segobriga imperial. fueron dos asentamientos con vidas sucesivas. Sin embargo, no creo que estemos ante dos emplazamientos consecutivos de una misma entidad politica. sino ante dos ciudades diferentes como sus monedas indican. A mi juicio existe una continuidad interna incontrovertible entre las monedas de sekobirikes, SEGOBRIS y SEGOBRICiA, sobre todo por sus tipos monetales - auténticos emblemas de las ciudades-. pero también por su metrologia, su arte, etc., mostrando que estamos ante una misma entidad politica como la permanencia del nombre y su perfecta secuencia etimológica indican. No veo por qué buscar en Carbica la prehistoria de Segobriga cuando ella estả tan clara en sekobirikes. Respecto a las semejanzas artisticas con Carbica, es indudable que existen, aunque me parecen más exactas las que Villaronga propuso en 1978 con Clunia (figuras 2.5 y 7 ), pero es indudable que ello abre un importante campo de discusión que habremos de seguir en el futuro. La secuencia metrológica entre Carbica y Segobriga, es sin duda cierta, pero ello puede deberse, sin más, a la pertenencia a un mismo patrón monetal, el celtibérico, en dos o tres fases sucesivas e inmediatamente anteriores a la implantación del sistema augústeo.

Gracias a los datos que me ha proporcionado personalmente Villaronga poseo los pesos de la emisión de Clunia que, comparados con los publicados por él en el articulo citado para las otras dos cecas, dan los resultados siguientes:

$\begin{array}{lrc} & \text { Peso medio } & \begin{array}{c}\text { Intervalo de } \\ \text { confianza }\end{array} \\ \begin{array}{l}\text { Clunia (fig. 5) } \\ \text { Contrebia Carbica }\end{array} & 12,63 & 11,87 / 13,39 \\ \quad \text { fig. 6) } & 8,83 & 7,63 / 10,04 \\ \text { Segobris (fig. 2) } & 8,73 & 8,10 / 9,36 \\ \text { Segobriga (fig. 3) } & 10,12 & 9,48 / 10,75 \\ \text { Segobriga (fig. 4) } & 10,67 & 9,85 / 11,49\end{array}$

Es evidente que la acuñación más antigua, modelo de las siguientes, es la de Clunia, y que tras ella y en una secuencia muy cercana se hallan Carbica y Segobris. Tras esa emisión se inicia la metrologia augústea de $10 / 11 \mathrm{gr}$. Tenemos aqui un testimonio más de las relaciones intimas entre el núcleo de la Celtiberia y la Celtiberia carpetana, sólo futuros hallazgos y nuevas ideas podrán esclarecer el problema.

\section{TESTIMONIOSESC RITOS}

El texto más explicito sea quizás el de Plinio -3.25-donde enumera los pueblos que concurren en el convento juridico de (artagonova "...los oretani. cognominados germani; los segobrigenses, que forman la cabeza de la Celtiberia: los toletani. que estan sobre el rio Tajo..." ". No hay duda de que la Segobriga citada aqui debe bustarse en la Meseta sur, al este de Toledo y lindante con los oretanos cuya ciudad mas importante, Oretum, es Granátula no lejos de Cabeza de Ciriego. La segunda cita de Plinio -6, 160- trata de una piedra especular de gran calidad que producia la Hispania Citerior, que efectivamente se ha localizado en los alrededores de Segobriga. También Ptolomeo -57-parece situar Segobriga en esa zona, puesto que sólo la distanciaria de Valeria, cuya localización en la Valera de Cuenca si es clara, un grado, y aunque sus imprecisiones geográficas son evidentes, es éste un dato válido para no llevarla muy lejos de la Valeria conocida. Por lo tanto, los datos tardíos, digamos imperiales, referidos a la Segobriga imperial parecen coincidir en situarla en Cabeza de Griego, o cerca de ella.

Otra muy distinta es la información que nos proporcionan los datos literarios referentes a la Segobrix republicana que parecen coincidir en Ilevarla a la Meseta norte, y entremezclarla, en los pocos casos en que la citan, con ciudades que hoy localizamos con toda seguridad en la Celtiberia de Castilla la Vieja. La referencia más antigua se nos ha conservado en un historiador tardio, Frontino -Strat. 4,5,22- donde narra el pasaje en que Viriato, tras exigir ayuda de Segovia y serle denegada, se dirige a Segobriga donde tambien es rechazado Peroquizás sea el lacónico texto de Estrabón -3,4,13-el más preciso: «De las cuatro naciones en que están divididos los keltiberes, la más poderosa es la de los arouákoi, que habitan la región oriental y meridional y son limitrofes con los karpetanoi y con las fuentes del Tágos. La más famosa de sus ciudades es Nomantia ....También los lusones están al oriente. limitrofes también ellos mismos con las fuentes del Tajo. De los arouákoi son las ciudades de Segeda y de Pallantia. ... Tanto Segobriga como Bilbilis son ciudades de los keltiberes; en los alrededores de las cuales lucharon Métellos y Sertórios" ${ }^{36}$.

\footnotetext{
"Trad. A. Garcia y Bellido, La España del siglo I de nuestra Eira. Madrid. 1947.

16 Trad. de A. Garcia y Bellido, cit. nota anterior. Sólo para facilitar ahora una más detallada discusión he cambiado parte de la versión castellana, plegándome más al texto de Estrabón que a una versión literaria. Las partes de mi traducción, confirmada por J. de Hoz a quien agradezco su ayuda, las he señalado en cursiva.
} 
El texto deja muy claro que la Celtiberia que describe Estrabón, probablemente la de Polibio, es limitrofe por el sur con las fuentes del Tajo y por el este con los Lusones, quienes a su vez también limitan por el mediodia con el Tajo ${ }^{37}$. Es decir que los celtiberos no debian situarse al sur del curso alto del Tajo, donde sin embargo si se hallaban los carpetanos, vecinos de los arévacos por el norte, como la fuente deja claro. La ubicación de Segohrix en plena provincia de Cuenca está, según el texto de Estrabón, fuera de lugar pues la situaría en Carpetania ${ }^{i x}$. Esta es también la opinión explicita de Schulten «Segobriga pertenece a Celtiberia sólo en sentido geográfico, si se llama "celtiberia» toda la Meseta, mientras que politicamente Celtiberia se limita a los valles del Duero y Jalón, y Segobriga pertenece a los Carpetanos...Bilbilis sí está en Celtiberia» ${ }^{34}$. Este mismo equívoco se plantea con Sigüenza, estando ésta todavía mucho más al norte que Segobriga, y sin embargo Polibio - 10,7,4- cita la ciudad en Carpetania ${ }^{40}$. Amén de que Estrabón añade que tanto Segobriga como Bilbilis son ciudades celtibéricas, y que en las cercanias de ambas lucharon Metelo y Sertorio, dándonos una proximidad de ambas ciudades, que como ya se ha comentado muchas veces, hace dudosa la ubicación de Segobrix en Cabeza de Griego, por ejemplo para A. García y Bellido: «Segobriga es de dificil identificación. Para alguno es Segorbe...para otros Cabeza de Griego...La Segobriga de Strabón no parece ser la de Valencia, y a caso tampoco la de Cuenca pues la cita como próxima a Bilbilis... Habria que suponer otra, o corregir por por Segontia (Sigüenza), lo que tampoco satisface...). Si a esos datos, sumamos el de Frontino que cita Segobriga como objetivo siguiente a Segovia en las exigencias de Viriato, veremos que Sego-

\footnotetext{
${ }^{17}$ Probablemente se refiere al Tajuña, más norteño que el Tajo. cf. A. Schulten, FHA VI, 248.

${ }^{3 *}$ No se me oculta lo problemático de esta afirmación, aunque la expansión de los celtiberos hacia el sur, tanto en occidento como en oriente, ha sido un tema bibliográfico reiterativo (Cf. con abundante bibliografia, J. M. Blázquez, "La expansión céltica en Carpetania, Baetica, Levante y sus causas", Celticum III. supl. Ogam 1962, pp. 409-28; S. Valiente y L. J. Balmaseda, "Hacia una delimitación de la Carpetania en la Edad del Hierro II", Homenaje al Prof. M. Almagro, III, 135-42). Parece probable que los datos que tenemos sobre la Celtiberia alto-republicana permitan situarla al norte de las fuentes del Tajo, aunque evidentemente con posterioridad hubo una expansión natural, o dirigida, hacia el sur que sin embargo no conlleva la "cultura celtibérica» primigenia. Las ciudades de Ercavica, Valeria y Segobriga, núcleos urbanos celtibéricos para tiempos imperiales, no han dado por ahora cultura material celtibérica republicana.

${ }^{39}$ FHA VI, p. 250.

${ }^{40} \mathrm{Cf}$. también nota anterior p. 248 .
}

hrix debe buscarse sin duda en la Meseta norte. En la referencia de Ptolomeo arriba citada, éste cita la ciudad como próxima a Bursao (Borja) lo que evidentemente es un error para tiempos imperiales, pero muy expresivo si pensamos que está utilizando fuentes republicanas.

Los epigrafes recogidos en Cabeza de Griego proporcionan algunos testimonios más que se deben interpretar en la misma dirección ${ }^{+1}$. En dos lápidas funerarias se citan dos diferentes personajes con el étnico (eltiber/a, que en uno de los casos es un cognomen ( $\mathrm{n}^{\circ} 78, C I L$ II 5881 ) y en el otro un nomen ( $\mathrm{n}^{\circ} 82, C I L$ 3132), pero es indudable que ambos deben interpretarse como apelativo de gentes foráneas dentro del habitat, $\mathrm{y}$ asi lo comentó $\mathrm{A}$. Tovar: «La distribución de Celtiber, Celtibera, siempre, salvo dos ejemplos en Uclés, en la frontera meridional, lejos de Celtiberia, parece confirmar que el uso del étnico no es natural que se dé en el territorio del étnico mismo" ${ }^{42}$. Los otros paralelos que M. Almagro recoge para este étnico, Celtiher/a, proceden de Caldas de Reyes (Pontevedra) - CIL II 2545-, Isona (Lérida) -4464-, Jerica (Castellón) -6067-, Barcelona -6188-, e incluso de A frica - CIL VIII 3690-, siempre en ejemplos aislados, siendo en Segobriga el único sitio donde el apelativo se repite, lo que debe indicar una más íntima conexión con la Celtiberia propia, lógico si la parte nuclear de la población procedía de esas tierras ${ }^{43}$. No se saben las fechas de estas dos inscripciones, pero es posible que los epígrafes con este étnico sean muy posteriores al traslado de población a Segobriga, con un lapso de tiempo suficiente como para considerar a los celtiberos ya como foráneos. Otros étnicos, indicativos una vez más de gentes extrañas, son recogidos por Almagro en las lápidas de la ciudad, asi Cantaber ( $n^{\circ} 79$ y 80), Bilbilitanus ( $\left.\mathrm{n}^{\circ} 78\right)$, Gallus (10), Toletanus ( $\left.\mathrm{n}^{\circ} 72\right)$. Des-

${ }^{4}$ Todo éste es material recogido en publicación por M. Almagro Basch, Segohriga II. Inscripciones ibéricas, latinas paganas y latinas cristianas. EAE, 127, 1984. El A. da una numeración interna que es la mantenida aqui.

${ }^{42}$ A. Tovar, «El nombre de celtas en Hispania», Homenaje a A. Garcia y Bellido. III, Revista de la Universidad Complutense. Madrid 1977, p. 177

${ }^{4}$ Un testimonio más, procedente de Magacela (Badajoz) puede añadirse hoy: Cantia Celtibera Emeritensis en A. Recio Veganzones \& J. Curbera, «Los Partidos Triunfantes del franciscano Juan Mateo Reyes Ortiz de Tovar y su valor en la antigua epigrafia extremeña" Anas, en prensa. Agradezco a los autores la facilidad que me han dado para utilizar el manuscrito antes de su publicación. Como bien comentan. Cantia es un gentilicio de tipo céltico, y yo creo que Celtibera debió aqui constituir un cognómen étnico, determinativo de gentes exógenas en origen, ya arraigadas en el territorio por lo menos en la generación de Cantia, como indica el adjetivo Emeritensis. 
carto sin embargo la propuesta de lectura legion(ensis) del n" 43 A y B como étnico".

\section{CONCLLSIONES}

Documentos de variada indole parecen pues disociar geograficamente la ciudad Segohrix de tiempos republicanos de la Segobriga Imperial. lo que podria indicar dos ciudades homónimas, hecho muy posible dada la vulgaridad de sus componentes, pero las monedas dan la impresión de pertenecer, por su homogeneidad, a una misma entidad politica. La explicación que yo aqui ofrezco, me parece la única lógica por ahora. La ciudad republicana de Segobrix, hubo de estar situada en la mesopotamia del alto Duero y el Pisuerga, cerca de Clunia con la que hemos visto tiene tantas relaciones, pero más de Palencia donde los porcentajes de sus monedas son los más altos y a cuyo norte no aparece sino moneda de sekohirikes, como por ejemplo en Amaya. Sin embargo, la Segobriga imperial no ha dejado alli ningúna huella, más bien ha ocasionado un vacio monetal que ha sido substituido por otras cecas cercanas. Estos datos negativos, más la presencia de moneda de Segobriga en Cabeza de Griego, y el de su relación por los resellos con otras cecas imperiales del sur, unidos a las referencias literarias de época imperial, que sin duda sitúan Segobriga en la antigua Carpetania, podrían indicar la ubicación de la ciudad en la provincia de Cuenca, tras un traslado de población desde el núcleo de la Celtiberia.

Sabemos que los traslados de población en época romana no son excepcionales, y que fue el método para la fundación de Palma y Pollentia llevada a cabo por Metello con el trasvase desde la Peninsula de 3.000 colonos hispano-romanos. Si estas ciudades fueron colonias fundadas por deductio no está claro, pues aunque Mela -2,124- asi las Ilama, Plinio -3,77- las cita como oppida. Más traslados de población entre los artabros por motivos socio-politicos son citados por Estrabón -3,3,5. Pero en íntima relación con nuestro caso, por tratarse de sucesos de las guerras sertorianas y por haber mantenido la nueva fundación el topónimo original, está el asentamiento de antiguos soldados de Sertorio en las cercanías de Lugdunum Convenarum, en una ciu-

\footnotetext{
${ }^{4}$ Este epigrafe es uno de siete fragmentos pertenecientes a una inscripción monumental dedicatoria del teatro, donde por las varias menciones a cargos y asuntos legionarios, la palabra LEGION pudo referirse, no a un étnico legion(ensis), que tendria que ser muy tardio, sino a un eargo o referencia militar.
}

dad Ilamada Calagorris al igual que la Calagurris rebelde asediada y destruida por los romanos *. Que Segobrix, donde tanto denario en las guerras sertorinas se acuño y al lado de la cual lucharon Sertorio y Metelo, fuese arrasada y su población trasladada a zona menos nuclear que el centro de la Celtiberia, es naturalmente una hipótesis, que sólo futuras excavaciones en la propia (abeza de (iriego y en otros centros de la Carpetania podrán dilucidar, aunque los datos contundentes habrán de proceder sin duda de la propia Celtiberia.

\section{$A D D E N D U M$}

Ya en prensa este articulo se ha publicado el libro de F. Romero, C. Sanz y Z. Escudero (edits.), Arqueologia vaccea, Valladolid 1993, donde se recogen minuciosamente los tres tesoros - joyas y monedas - de Padilla de Duero. Las monedas son detalladamente estudiadas por R. Martin Valls en pp. 403-412, 416-420 y 44I-45I. Proceden de tres diferentes puntos de Padilla, y uno de ellos, el tercero, no contiene moneda. En el primero aparecieron 30 piezas de sekobirikes, 17 de turiaso, 4 de arekorata, 3 de arsaos y 1 de belikio. El segundo, 4 de sekobirikes, 3 de turiaso, 3 de arsaos y 2 de arekorata. Las cifras globales coinciden con las del cuadro adjunto que estaban tomadas de opp.citt. en n. 7. También tarde para incluirlo en el mapa y el cuadro, me llega la noticia de dos tesorillos de El Castro del Chano (León), con una alta mayoría de moneda de sekobirikes, of. datos en nota 7 .

\section{LISTA DE ABREVIATURAS USADAS}

$\begin{array}{ll}\begin{array}{l}\text { A } \\ \text { AEA }\end{array} & \begin{array}{l}\text { Ampurias (Barcelona) } \\ \text { Archivo Español de Arqueologia (Ma- } \\ \text { drid) }\end{array} \\ \text { AEAA } & \begin{array}{c}\text { Archivo Español de Arte y Arqueologia } \\ \text { (Madrid) }\end{array} \\ \text { AN } & \text { Acta Numismática (Barcelona) } \\ \text { ARRCH } & \text { C. Blázquez, «Addenda a los Roman Re- } \\ & \text { publican Coins Hoards», AN 17-18, } \\ & \text { 1988, pp.l05-142 } \\ \text { BASE } & \text { Boletin Arqueológico del Sudeste Espa- } \\ & \text { ñol (Cartagena) } \\ \text { BRAH } & \text { Boletin de la Real Academia de la His- } \\ & \text { toria (Madrid) }\end{array}$

4s A. Garcia y Bellido, "Hispanos en el sur de Francia» $B R A H$ 1955, pp. de separata 7-16. 
B.S.1.1 Boletindel Seminario de Estudios de Arte 1. Arculeologia (Valladolid)

(C.AL T. Mañanes, Contribución a la Carta A)queolígica de la provincia de León. Centro de Estudios de Investigacion San Isidoro, León 1977.

(EP C. Sanz Minguez é alii. C'atálogo de la Exposición de Pénafiel. Padilla de Duero, Valladolid 1989.

CMII R. Martín Valls, La circulacion monetaria ihérica, Valladolid 1967

(NI Congreso Internacional de Numismaitica (lugar de ed. variable)

GN Gaceta Numismática (Barcelona).

G.M. C. M. León: Gómez Moreno, Catálogo Momumental de León, 2 vols., León 1926.

Misc., Misceláneas de Arte y Arqueologia, Madrid 1449

Guadán A. de Guadán, Numismática ibérica é ibero-romana, Madrid 1969

$H M$

F. Mateu y LLopis, "Hallazgos Monetarios») I-VI en Ampurias, 1942 1951, en Numario Hispánico VII-XX 1952-1967, y en Numisma XXI-XXV. 1967-1979

Maluquer J. Maluquer, Carta Arqueológica de España. Salamanca 1956
MII Madrider Mitteilungen. Deturshes Archäologisches Institut, (Heidelberg)

MALAP Me'morias de los Museos Arqueologicos provinciales, (Madrid)

MPP Museo de Ponteredra. (Pontevedra)

NH Numario Hispanico, (Madrid)

Nieto G. Nieto Gallo, El oppichum de Iruña, Vitoria 1958

Numis. $\quad$ Numisma (Madrid)

Nummus Nummes (Oporto)

Sacristán J. D. Sacristán, La edad del Hierro en el valle medio del Duero, Rauda (Roa. Burgos), Valladolid 1986, II SIAV I. Barandiarán, «Notas sobre numismatica antigua en Guipúzcoa», II Semana Internacional de Antropologia Vasca, Bilbao 1972, pp. 287-302

Taracena B. Taracena, Carta Arqueológica de España. Soria, Madrid 1941

Ybarra J. Ybarra, Catálogo de Monumentos de Vizcava, Bilbao 1958

Zephyrus M.P. Garcia-Bellido, «Tesorillo salmantino de denarios ibéricos", 1974, 379-395

Zobel J. Zobel de Zangroniz, Estudio histórico de la moneda antigua Española desde su origen hasta el Impero romano, Madrid 1878-80 